\title{
EDITORIAL
}

\section{A letter to readers and authors of Journal of Forestry Research}

Chuanping Yang

Dear readers and authors:

Happy New Year for 2014!

Journal of Forestry Research (JFR) was created in 1990, co-sponsored by Northeast Forestry University and Ecological Society of China, and cooperatively published with Springer-Verlag GmbH. Through 24 years of growth and development, JFR has become a leading journal in forestry science in China. Since 2007, the editorial office of JFR has collaborated with Springer-Verlag to bring the online and print journal to our increasing international audience. JFR has become an international journal with a growing diversity of contributing authors, editors, and editorial advisory board members. JFR is an important and strictly peer-reviewed forestry journal that accepts original contributions and publishes the most current research results related to forestry. Approximately 75 per cent of the papers published in the journal are by international researchers (authorship covers more than 50 countries); the balance is contributed by Chinese scientists. Beginning with Vol. 24 (1) 2013, JFR has been selected for coverage in two Thomson Reuters products, Science Citation Index Expanded (SciSearch ${ }^{\circledR}$ ) and Journal Citation Reports/Science Edition. In total, JFR has been indexed or abstracted by 20 international databases.

In 2013, the JFR obtained project funding (2013-2015) from the government of China. This project is to support China's international journals to improve their international influence. The key point for improving the impact factor of a journal is to publish high quality and frequently cited papers. We have organized an international editor group and made a plan for improving the impact factor of JFR. During the project we will specially collect 20 papers (review articles and/or research papers) from well-known forestry experts and scholars each year. The specially invited submissions will enjoy primacy of publication. We have established a reward system for attracting high quality papers. Twenty top cited papers in Web of Science will be selected and awarded each year. We also welcome well-known forestry experts to contact us for publication of groups of papers on a specified subject for special issues of JFR. The editorial content of JFR focuses on forest management, forest ecology, forest soils, tree genetics and breeding, forest disease and insects, forestry mathematics, forest wildlife ecology and management, wood science, and forest engineering. The journal will not publish papers related to forestry economics, medicinal plants, horticulture, gardening, aquatic organism, furniture, and other subjects addressed in detail by other journals. To improve the academic quality of the journal, we will strengthen peer review of manuscripts and increase the rejection rate of submissions.

Since its beginning in 1990, JFR has made a great progress. I would like to take this opportunity to explicitly thank all reviewers and authors who have contributed to the journal and to express my most sincere thanks to our editorial group, editorial board members, and all who have supported the journal. Also I want to specially thank my colleague Prof. Ruihai Chai, the deputy editor-in-chief, who has worked on JFR for 20 years, for his persistent efforts to develop the journal. As a new journal indexed by SCI, JFR ushers in new opportunities and challenges. We have set up a goal to build JFR into an outstanding international journal. To reach this goal we hope to obtain strong 
support from forestry experts around the world. We welcome you to submit your research work to JFR. Also, it would be appreciated if you draw attention and cite the papers from the JFR. With your support, the international profile of Journal of Forestry Research will continue to grow in future.

相清方

Chuanping Yang

Editor-in-Chief of Journal of Forestry Research

President of Northeast Forestry University

January 15,2014 